Chirurgia (2021) 116: 689-699

No. 6, November - December

Copyright@ Celsius

http://dx.doi.org/10.21614/chirurgia.116.6.689

\title{
Nonoperative Treatment of Abdominal Trauma Involving Liver and Spleen
}

\author{
Dan Cartu, Dragos Margaritescu, Sarmis Sandulescu, Tudor Bratiloveanu, Sandu Ramboiu, Marius Bica, \\ Eugen Georgescu, Catalin Dudu, Stefan Patrascu, Silviu Bordu, Alexandru Goganau*, Valeriu Surlin, \\ Daniela Marinescu
}

University of Medicine and Pharmacy of Craiova, Emergency Hospital, $1^{\text {st }}$ Surgery Department, Craiova, Romania

*Corresponding author: Alexandru Goganau, MD University of Medicine and Pharmacy of Craiova, Emergency Hospital $1^{\text {st }}$ Surgery Department, Craiova Romania

E-mail: goganau_alex@yahoo.com

\section{Rezumat}

Tratamentul non-operator al traumatismelor abdominale care implică ficatul și splina

Introducere: Managementul acestui tip de traumatisme a evoluat considerabil, mai ales odată cu apariția radiologiei intervenționale (angiografie, embolizarea arterei splenice - SAE) dar şi a conceptului de tratament non-operator (TNO), definit ca o urmarire a leziunilor, fără a se interveni chirurgical.

Material şi Metodă:Am stabilit o strategie de abordare a cazurilor de traumatisme cu leziuni prin tratament non-operator (TNO). Am aplicat TNO la 13 pacienți din $50(26 \%)$, dintre care 8 pacienți cu leziuni ale splinei şi 5 pacienți cu leziuni ale ficatului. Majoritatea leziunilor au fost de gradul II (8 cazuri), 2 cazuri s-au încadrat în gradul I şi 3 cazuri în gradul III.

Rezultate: A existat un singur caz abordat TNO, la care s-a intervenit chirurgical la 48 de ore de la internare. La doi pacienți cu extravazarea de substanță de contrast la CT şi la angiografie $\mathrm{s}$-a efectuat angioembolizarea arterei splenice, cu bune rezultate. CT de control s-a efectuat la o perioada ce a variat între 24 ore şi 5 zile de la internare. Perioada medie de internare a pacienților abordati prin TNO a fost de 6,6 zile.

Concluzii: Examenul CT cu substanța de contrast rămâne baza inițierii TNO, furnizând datele necesare referitoare la gradul leziunii hepatice sau splenice, amploarea colectiilor hematice, extravazarea substanței de contrast dar reprezintă şi explorarea imagistică esențială în evaluarea eficienței TNO. Angioembolizarea poate fi practicată cu succes în cazurile unde 
examenul CT şi angiografia arată extravazarea substanței de contrast. A existat un singur caz inclus în TNO, la care s-a intervenit pe cale laparoscopică, dar majoritatea autorilor subliniază că acesta nu trebuie considerat un eşec al metodei.

Cuvinte cheie: tratament non-operator, traumatisme abdominale, radiologie interventionala

\begin{abstract}
Introduction: The management of this type of trauma has evolved considerably, especially with the introduction of interventional radiology (angiography, splenic artery embolization - SAE) but also the concept of non-operative treatment (NOT), defined as a follow-up of injuries, without surgery. Material and method: We have established a strategy for dealing with cases of abdominal trauma with injuries by non-operative treatment (NOT). We applied NOT to 13 patients in 50 (26\%), of which 8 were patients with spleen injuries and 5 were patients with liver damage. Most of the lesions were grade II (8 cases), 2 cases were grade I and 3 cases were grade III.

Results: There was only one case dealt by NOT, in which surgery was performed 48 hours after admission. In two patients with extravasation of the contrast agent on CT and angiography, angioembolization of the splenic artery was performed, with good results. Control CT was performed at a period that varied between 24 hours and 5 days after admission. The average period of hospitalization of patients approached by NOT was 6,6 days.

Conclusions: Contrast-enhanced CT examination remains the basis for NOT initiation, providing the necessary data on the degree of liver or splenic lesion, the size of blood collections and extravasation of the contrast substance but is also the essential imaging exploration in assessing NOT efficacy. Angioembolization can be successfully performed in cases where CT examination and angiography show contrast extravasation. There was only one case included in the NOT, which was operated laparoscopically, but most authors emphasize that this should not be considered a failure of the method.
\end{abstract}

Key words: non-operative treatment, abdominal trauma, interventional radiology

\section{Introduction}

Severe abdominal injuries associate approximately $15-20 \%$ of injuries found in traumatology, being associated with an increased mortality of up to $20 \%$. In Europe, the majority is represented by closed abdominal injuries, the most common cause of death in abdominal injuries being internal hemorrhage, incriminated in over $80 \%$ of deaths. In closed abdominal traumas, spleen and liver lesions are found in proportions ranging from $33-46 \%$ according to the authors (1). In Europe, most abdominal injuries occur in traffic accidents (about 80\%), the rest from sports accidents $(8 \%)$ or falls from height $(12 \%)(1,2)$. The mechanisms by which the lesions of the parenchymal organs occur are varied, from percussion (direct shock), to sudden deceleration, in case of falls from height. It is believed that at present, the management of severe abdominal trauma can be improved in such a way as to reduce mortality by up to $50 \%(1,3)$. The management of this type of trauma has evolved considerably, especially with the introduction of interventional radiology (angiography, splenic artery embolization SAE) and also the concept of non-operative treatment (NOT), defined as a follow-up of injuries, without surgery . It starts from the scene of the accident and continues uninterrupted in the emergency room, in the 
intensive care and surgical ward, the approach being always multidisciplinary, with the contribution of ambulance physicians, emergency medicine specialists, resuscitators, surgeons or interventional radiologists $(1,2)$.

At present, it is considered that a case of closed abdominal trauma has a surgical indication if hemodynamic instability persists, despite active resuscitation measures. These measures are quantified very clearly, having as objectives, the obtaining of two safe venous accesses, the measurement of $\mathrm{O}_{2}$ saturation, the invasive measurement of the arterial pressure, and in case of need the oro-tracheal probe. If the patient stabilizes hemodynamically, active monitoring is continued, permanent monitoring of diuresis, upper digestive aspiration, electrocardiogram, hemodynamic parameters, biological data and hypothermia is countered. Imaging investigations can be continued to highlight the presence of a possible hemoperitoneum $(1,4)$.

We have tried to gradually implement all these new principles and protocols that are required lately in abdominal traumatology, in the Surgery Clinic I of Clinical Emergency County Hospital of Craiova, taking into account the limitations imposed by the endowment of our hospital unit. One of the important limitations was the availability of interventional angiography and embolization only for $8 / 24$ hours, as well as the small number of specialists to provide this type of care on an ongoing basis. In this context, we applied a protocol adapted to the existing possibilities.

The aim of the study is to highlight the possible advantages obtained by applying modern diagnostic and therapeutic methods, as well as to improve and quantify at a higher level adapted to the applied protocols.

\section{Material and Method}

Our study is a retrospective one, based on the existing cases in the Surgery Clinic I in Craiova over a period of 5 years (2016-2021). The study included 50 cases of abdominal trauma (blunt and penetrating) involving the liver and/or spleen, recorded during this period, operated or treated non-operatively (NOT). The 50 cases accounted for $47.17 \%$ of the total 106 cases of abdominal trauma recorded during this period. There were 38 men and 12 women. The causes of injuries involving the spleen and liver were: 32 traffic accidents (64\%), 7 physical assaults (14\%), 6 work accidents (12\%), 2 animal assaults (4\%), 2 falls from a height (4\%) and a hunting accident with a gunshot wound with hepatic involvement (2\%). The degrees of spleen and liver lesions were quantified according to the AAST (American Association for the Surgery of Trauma) classifications for traumatic injuries of the spleen and liver (Tables 1, 2). There were 41 traumas with spleen injuries $(82 \%)$ and 10 cases with liver injuries (20\%), with the mention that in one case both organs were

Table 1. The degree of spleen injuries in our study, according to the AAST (American Association for the Surgery of Trauma) classification for traumatic spleen injuries (compared to the 41 splenic injuries)

\begin{tabular}{|c|c|c|c|c|}
\hline Grade & Hematoma & Dilacerations & Vascular injury & Number of cases/\% \\
\hline I & Subcapsular $<10 \%$ of surface & Capsular, <1 cm deep & No & $7 / 17.1$ \\
\hline$\|$ & $\begin{array}{l}\text { Subcapsular, between } 10 \%-50 \% \text { of surface } \\
\text { Intraparenchymal, }<10 \mathrm{~cm} \text { in diameter }\end{array}$ & $\begin{array}{l}\text { Parenchymal, between 1-3 } \\
\mathrm{cm} \text { deep and }<10 \mathrm{~cm} \text { long }\end{array}$ & No & $15 / 36.6$ \\
\hline III & $\begin{array}{l}\text { Subcapsular ruptured or }>50 \% \\
\text { of surface or expansive } \\
\text { Parenchymal rupture } \\
\text { Intraparenchymal }>10 \mathrm{~cm} \text { or expansive }\end{array}$ & Parenchymal, $<3 \mathrm{~cm}$ deep & Possible & $12 / 29.3$ \\
\hline IV & & $\begin{array}{l}\text { Laceration affecting the vessels in the hilum, } \\
\text { causing a devascularization }>25 \%\end{array}$ & Yes & $4 / 9.8$ \\
\hline V & & $\begin{array}{l}\text { Broken intraparenchymal hematoma with } \\
\text { active bleeding. Injury to segmental or } \\
\text { hilar vessels, leading to a complete infarction }\end{array}$ & $\begin{array}{l}\text { In the splenic } \\
\text { pedicle }\end{array}$ & $1 / 2.4$ \\
\hline $\mathrm{VI}$ & & Spleen avulsion & $2 / 4.9$ & \\
\hline
\end{tabular}

Note: Advances by one degree for multiple spleen injuries greater than grade III 
Table 2. The degree of liver damage according to the AAST (American Association for the Surgery of Trauma) classification for traumatic liver injury (relative to the 10 liver lesions).

\begin{tabular}{|c|c|c|c|c|}
\hline Grade & Hematoma & Dilacerations & Vascular injury & Number of cases/\% \\
\hline I & Subcapsular $<10 \%$ of surface & Capsular $<1 \mathrm{~cm}$ deep & No & $2 / 20$ \\
\hline$\|$ & $\begin{array}{l}\text { Subcapsular between } 10 \%-50 \% \\
\text { of the surface } \\
\text { Intraparenchymal }<10 \mathrm{~cm} \text { in diameter }\end{array}$ & Parenchymal $1-3 \mathrm{~cm}$ deep and $<10 \mathrm{~cm}$ long & No & $4 / 40$ \\
\hline III & $\begin{array}{l}\text { Subcapsular ruptured or }>50 \% \text { of surface } \\
\text { or expansive } \\
\text { Parenchymal ruptured } \\
\text { Intraparenchymal> } 10 \mathrm{~cm} \text { or expansive }\end{array}$ & Parenchymal $>3 \mathrm{~cm}$ deep & No & $2 / 20$ \\
\hline IV & & $\begin{array}{l}\text { Parenchymal, affecting } 25 \%-75 \% \text { of a lobe } \\
\text { or } 1-3 \text { unilobar segments }\end{array}$ & No & $1 / 10$ \\
\hline V & & $\begin{array}{l}\text { Parenchymal, involving }>75 \% \text { of a lobe } \\
\text { or }>3 \text { unilobar segments }\end{array}$ & $\begin{array}{c}\text { Subhepatic veins, } \\
\text { Retrohepatic vena cava }\end{array}$ & $1 / 10$ \\
\hline $\mathrm{VI}$ & & & Hepatic avulsion & 0 \\
\hline
\end{tabular}

Note: Advances by one degree for multiple liver damage greater than grade III

injured. Of the 50 abdominal injuries included in the study $34(68 \%)$ were associated with other region injuries, as follows: 22 thoracic injuries (44\%), 12 head injuries (24\%) and 10 cases of limbs and pelvis injuries (20\%). In 12 cases $(24 \%)$ other lesions of the abdominal organs were associated: 2 cecum injuries (4\%), 4 renal contusions (8\%), 2 perforations of the small intestine (4\%), 2 ruptures of the colon (4\%), a gallbladder contusion (2\%) and an adrenal gland contusion (2\%). Hemorrhagic shock was encountered in 9 patients (18\%): a grade V spleen rupture, 2 grade IV liver ruptures, 4 grade IV spleen ruptures, and 2 spleen avulsions. Table no. 3 shows the classification of patients according to the hemoglobin level at the time of admission (Table 3). Leukocytosis at admission ( $\mathrm{L}>11000$ $/ \mathrm{mmc}$ ) was found in 35 of the 50 cases. FAST ultrasound was performed in 31 cases $(62 \%)$;
Table 3. Hemoglobin level at admission

\begin{tabular}{cc}
\hline Hemoglobin $(\mathbf{m g} / \mathbf{d l})$ & Number of cases $/ \%$ \\
\hline$<8$ & $13 / 26$ \\
\hline $8-10$ & $8 / 16$ \\
\hline $10-12$ & $15 / 30$ \\
\hline$>12$ & $14 / 28$ \\
\hline
\end{tabular}

the results are presented in Table 4. The contrast-enhanced CT examination was performed in 44 cases ( $88 \%$ ), the results being presented in Table 5. Blood transfusions (at least one unit of blood) were administered to 16 patients (32\%). We have established a case management strategy including diagnostic and/or therapeutic laparoscopy as well as nonoperative treatment (NOT), which is also the subject of our analysis. Patients were investigated by FAST ultrasound, computed tomography, and sometimes arteriography. We have established as indications for diagnostic

Table 4. Lesions highlighted by FAST ultrasound

\begin{tabular}{llll}
\hline Lesion & Haemoperitoneum & $\begin{array}{l}\text { Hematoma / } \\
\text { Perihepatic or perisplenic } \\
\text { blood collection }\end{array}$ & $\begin{array}{l}\text { Obvious damage } \\
\text { to the liver/ spleen }\end{array}$ \\
\hline Number of cases $/ \%$ & $9 / 29$ & $10 / 32.3$ & $19 / 61.3$ \\
\hline
\end{tabular}

Table 5. Lesions highlighted by contrast-enhanced CT examination

\begin{tabular}{llll}
\hline Lesion & Haemoperitoneum & $\begin{array}{l}\text { Hematoma / } \\
\text { Perihepatic or perisplenic } \\
\text { blood collection }\end{array}$ & $\begin{array}{l}\text { Obvious damage } \\
\text { to the liver/ spleen }\end{array}$ \\
\hline Number of cases $/ \%$ & $12 / 27.3$ & $9 / 20.5$ & $40 / 90.9$ \\
\hline
\end{tabular}


and / or therapeutic laparoscopy: suspicion of cavitary or parenchymal organ injury or mesenteric injury, the presence of hemoperitoneum or fluid in the peritoneal cavity in an amount of over $500 \mathrm{ml}$, in a hemodynamically stable patient, without major hemorrhage, apparently with single injury, no immediate life-threatening risk and no other associated severe trauma. We have associated lately NOT for grade I, II and III lesions of the parenchymal organs, which do not have a hemo-peritoneum larger than about $500 \mathrm{ml}$ described imagistically, hemodynamically stable or with a rapid favorable response to balancing measures. The protocol has been adapted to the possibilities of our hospital unit.

\section{Results}

We applied NOT to 13 patients from the total of $50(26 \%)$, of which 8 were patients with spleen injuries and 5 were patients with liver injuries. Most of the lesions were grade II (8 cases), 2 cases were grade I and 3 cases were grade III. In all patients undergoing NOT, a contrast CT examination was performed at admission (between 20-95 minutes after admission) which showed ruptures and tears of the spleen or liver in 6 cases, intraparenchymal or subcapsular hematomas in 7 cases, reduced hemoperitoneum (less than 500 $\mathrm{ml})$. In 2 cases, the extravasation of the contrast substance, evidenced tomographically and angiographically, required the distal splenic artery embolization (SAE) to be performed. FAST ultrasound was used in 9 cases as a first-line investigation, showing 4 lesions of parenchymal organs and 5 subcapsular hematomas of the spleen or liver. No patient to whom NOT was applied showed signs of bleeding shock. A single patient, with multiple trauma, multiple lung damage, hemopneumothorax, head trauma, and a third-degree rupture of the spleen, had a hemoglobin value below $8 \mathrm{~g} / \mathrm{dl}(7.7 \mathrm{~g} / \mathrm{dl})$. The latter was also the only unstable patient with traumatic shock and coma due to post-traumatic brain injury, but was still eligible for a NOT approach for the grade III spleen rupture, given the extent of the associated trauma. It was decided to perform distal SAE on this patient in the first 24 hours after the trauma, which went smoothly, in good condition. However, the patient's death occurred on the $6^{\text {th }}$ day of hospitalization due to complications related to the associated trauma. In all patients included in the NOT protocol, we performed CT tests with contrast at intervals ranging from 24 hours to 5 days. Except for the case presented above, we recorded a single failure of the NOT, in a patient with grade III spleen rupture, in which a control CT examination, with contrast substance, performed 48 hours after admission showed the formation of a significant hemoperitoneum, reason for which surgery was performed, performing a laparoscopic splenectomy and the lavage of the peritoneal cavity. 11 patients treated by NOT showed a favorable evolution, discharging at intervals that varied between 5 and 10 days, with an average of 6,6 days, with the recommendation to return for clinical and imagistic control. Compared to the entire study group (50 patients), we recorded 12 deaths (24\%), but 3 patients with spleen and liver damage grades V-VI died without being operated, in the emergency unit, due to cardiorespiratory arrest due to hemorrhagic shock. Another 7 patients with injuries of varying degrees of spleen and liver died from complications due to other traumas or associated injuries (ruptures of the colon and small intestine with fecal peritonitis and severe sepsis, head trauma with lacerations and cerebral hematomas and severe thoraco-pulmonary trauma with pulmonary ruptures and hydropneumothorax). Two patients, one with spleen avulsion and one with hepatic wound by gunshot, died in the first hours postoperatively because of the hemorrhagic shock associated with other existing severe lesions.

\section{Discussions}

The 50 cases of trauma involving the liver and spleen accounted for $47.17 \%$ of all abdominal injuries recorded during the study period, being at the upper range of the data provided 
by the literature (33-46\%) (1). Traffic accidents were the main cause, with almost two thirds of cases, also in accordance with data from the literature, which shows a percentage of about $80 \%$ of road accidents $(1,2)$. Almost $80 \%$ of the traumas were associated with traumas in other regions, and in some cases these associated traumas contributed decisively to the unfavorable evolution of the patients. In our study, 41 patients (82\%) arrived in the emergency department without signs of hemorrhagic shock. However, there were 4 cases of patients who, on arrival in the emergency department had a very severe general condition, in various degrees of coma, due to associated injuries, especially severe head injuries with cerebral tears, bruises or diffuse contusions. In the case of severe but non-shock traumatic injury, rapid initial clinical examination should look for signs of circulatory, respiratory, or neurological distress requiring appropriate emergency treatment. A chest X-ray and / or abdominal ultrasound FAST is performed in parallel with monitoring and balancing. The introduction of at least one peripheral intravenous catheter allows blood to be taken for laboratory testing. Subsequently, a central venous catheter and possibly a radial artery catheter for blood pressure monitoring should be placed if major blood loss is evident. The patient should be intubated, even on assisted ventilation, if necessary to ensure adequate analgesia and sedation. The prevention and / or correction of hypothermia is fundamental and is based on the measurement of the central temperature, which must be maintained at $35^{\circ} \mathrm{C}$, with the heating of all infusion fluids, ventilation gases and even the use of electric blankets. Bladder catheterization is performed after abdominal ultrasound and rectal examination have ruled out urethral trauma. Measurement of urine flow is an essential part of resuscitation, and measurement of intravesical pressure allows monitoring of intra-abdominal pressure (1). Our study shows that during the study period, FAST ultrasound was frequently used in the protocol applied to patients with abdominal trauma, the results being useful in assessing blood lesions and accumulations, but in most cases, we continued imaging investigation in stable or hemodynamically stabilized patients with CT examination with contrast. However, there were 5 situations in which FAST ultrasound was considered sufficient to resolve the diagnosis and to establish the therapeutic conduct. In these cases, FAST ultrasound revealed appreciable pneumoperitoneum, which associated with the general condition and clinical picture of the patients led to an indication for emergency surgery. FAST (Focused Assessment with Sonography for Trauma) ultrasound is known to highlight the presence of hemoperitoneum, splenic liver lesions, but also a possible pleural effusion, associated renal lesions or retroperitoneal collections. It has the great advantage that it can be repeated as needed at the patient's bedside. In recent years, Extended FAST or E-FAST (Extended Focused Assessment with Sonography for Trauma) has been used, which also looks for the presence of pleural effusion (fluid or gas). The level of evidence remains low and further studies are needed, in particular to determine its impact on patients' prognosis. A unicenter prospective study confirms low sensitivity ( $64 \%$ and $46 \%$, respectively) but good specificity $(94 \%)(5,6)$. A recent meta-analysis shows that the relevance of E-FAST to diagnose a thoraco-abdominal injury is good with a sensitivity of $74 \%$ and a specificity of $96 \%$, and for the detection of intra-abdominal effusion, the sensitivity is $68 \%$ and the specificity is $95 \%$ (7). A negative FAST does not rule out a less abundant discharge $(<500 \mathrm{~mL})$ and/or the presence of lesions of the parenchymal or cavitary organs, some of which may have a surgical indication. Likewise, a positive FAST does not characterize the nature of peritoneal effusion (urine, ascites). Although FAST makes it possible to make appropriate treatment decisions in the emergency department in more than $99 \%$ of cases, no study has yet been able to demonstrate a reduction in mortality associated with its use $(4,8,9)$. The PROMMT study looked at patients who met the criteria for inclusion in the study (transfusion of at least one blood 
unit in the first six hours) and who underwent a laparotomy within 90 minutes after a positive FAST. Delays related to the inpatientlaparotomy and FAST-laparotomy interval were both associated with a significant increase in mortality at 24 hours and 30 days $(4,8,9,10)$.

Contrast CT examination is the absolute rule in all patients with severe trauma, no initial hemorrhagic shock, or hemorrhagic shock but whose vital signs can be stabilized. In our study, there were only 6 cases $(12 \%)$ in which no CT examination was performed. In a case of penetrating abdominal wound with great omentum evisceration and leakage of intestinal contents through the wound, hemodynamically balanced, the indication for emergency surgery was clearly outlined and the CT examination was not considered imperative, the splenic lesion being diagnosed intraoperatively. Another 5 cases, which we presented above, benefited only from FAST ultrasound, which revealed important blood collections, the indication for surgery being urgent, in the first hour after admission to the emergency department. The usual indication for urgent laparotomy after a penetrating abdominal trauma is hemodynamic instability (systolic arterial pressure $<90 \mathrm{mmHg}$ and/or absent or transient response to volume balancing). In these patients, performing a $\mathrm{CT}$ scan delays the laparotomy by 31 to 90 minutes and could increase hospital mortality by more than $70 \%$, as evidenced by a retrospective analysis of the U.S. National Trauma Data Bank (U.S.NTDB) (11). In hemodynamic instability after closed abdominal trauma associated with profuse intra-abdominal effusion, the time to laparotomy increases the risk of death by $1 \%$ every 3 minutes (12). Contrast CT provides information on the volume of peritoneal effusion, spleen and liver damage, other abdominal organs and diaphragm, identifies persistent bleeding, highlighted by extravasation of the contrast agent, which may be an indication for angiography and embolization. The decision to perform emergency laparotomy is due to persistent hemodynamic instability, which requires continuous resuscitation, especially if the patient has certain risk factors (old age, cirrhosis, coagulation disorders). A review of the literature examining the value of CT for the diagnosis of parenchymal organ lesions shows $98 \%$ sensitivity and $98 \%$ specificity (9). In the context of severe abdominal trauma, performing a contrast-enhanced CT scan can quickly identify lesions with active bleeding and can obtain a complete assessment of the lesion to establish a therapeutic strategy (4, 10,13). A randomized study (REACT-2) aimed to demonstrate a $5 \%$ reduction in mortality when using a contrast CT scan of the whole body. The results of the study suggested a reduction in mortality of around $3 \%$, the REACT-2 study not having the ability to demonstrate the proposed difference but still suggests that we consider the benefits of mortality brought by the whole body CT examination $(4,10)$.

Non-operative treatment (NOT) has seen a steady increase in use, avoiding an invasive surgical procedure, as well as many of the postoperative complications of splenectomy, as well as the need for lifelong preventive measures against post-splenectomy infections. In the absence of active intra-abdominal hemorrhage and/or traumatic gastrointestinal perforation, it is recommended to perform a NOT in order to reduce morbidity and mortality. NOT has gradually established itself since the 1970s for abdominal trauma due to the development of CT examination, a better understanding of the mechanisms leading to complications and death, as well as the emergence of interventional radiology (14). The development of new therapeutic protocols would now make NOT possible for more than $80 \%$ of abdominal injuries, especially in the absence of hemorrhagic shock or suspected digestive perforation (15). In stable patients with closed abdominal trauma, NOT can be considered as first-line in most cases (4). In the presence of an active intra-abdominal hemorrhage diagnosed tomographically, it is recommended to consider, after a multidisciplinary consultation, an emergency hemostatic angioembolization. For stable patients with 
penetrating abdominal trauma, NOT may be similarly considered in the absence of documented active bleeding or suspected digestive and biliary, bladder or pyelocaliceal lesions. The presence of pneumoperitoneum suggests digestive tract damage and should therefore be considered for exploratory laparotomy (4). We tried NOT in 13 patients, selected and treated according to a protocol presented above, which took into account both the existing data in the literature, but also the real possibilities of our hospital. The evolution was favorable in 11 cases, the patients being discharged after periods that varied between 5 days and 10 days, with an average of 6.6 days. Except for the case of a patient with associated lesions, approached with NOT and who had SAE, who died of associated lesions, we recorded a single failure of NOT, in a patient with grade III spleen rupture, in which a CT examination, with contrast substance, performed 48 hours after hospitalization showed the formation of an important hemoperitoneum, which is why surgery was indicated, performing a laparoscopic splenectomy and lavage of the peritoneal cavity. However, secondary intervention (laparotomy, laparoscopy, endoscopy, interventional radiology) should not be considered a failure of the strategy (4). Even grade IV and V lesions may justify in some cases a carefully selected and responsible NOT including careful and repeated clinical-radiological monitoring.

In the 2 cases described above, we applied distal SAE, following the results that came from contrast CT tests, which highlighted the extravasation of the contrast substance. In both cases, the method proved to be effective, without adverse phenomena, the death occurring in one of the cases having completely different causes. The literature shows that in cases of documented active hemorrhage, hemostatic angioembolization significantly reduces the risk of NOT for splenic and liver lesions $(4,16,17)$. While some authors argue that preventive angioembolization could be very effective in certain liver injuries with moderate extravasation of contrast agent (18), others still consider it controversial in splenic
Table 6. Baltimore Classification of Vascular Injury Severity in Spleen Injuries (13)

\begin{tabular}{|c|c|}
\hline Grade & Criteria \\
\hline 1 & $\begin{array}{l}\text { Subcapsular hematoma }<1 \mathrm{~cm} \text { thick } \\
\text { Laceration }<1 \mathrm{~cm} \text { parenchymal depth } \\
\text { Parenchymal hematoma }<1 \mathrm{~cm} \text { in diameter }\end{array}$ \\
\hline 2 & $\begin{array}{l}\text { Subcapsular hematoma } 1 \text { to } 3 \mathrm{~cm} \text { thick } \\
\text { Laceration } 1-3 \mathrm{~cm} \text { deep in the parenchyma } \\
\text { Parenchymal hematoma with a diameter of } 1-3 \mathrm{~cm}\end{array}$ \\
\hline 3 & $\begin{array}{l}\text { Disruption of the splenic capsule } \\
\text { Subcapsular hematoma }>3 \mathrm{~cm} \text { thick } \\
\text { Laceration }>3 \mathrm{~cm} \text { in parenchyma depth } \\
\text { Parenchymal hematoma }>3 \mathrm{~cm} \text { in diameter }\end{array}$ \\
\hline $4 a$ & $\begin{array}{l}\text { Active intraparenchymal and subcapsular splenic bleeding } \\
\text { Splenic vascular lesions (pseudoaneurysm or arteriovenous fistula) } \\
\text { Spleen explosion }\end{array}$ \\
\hline $4 \mathrm{~b}$ & Active intraperitoneal bleeding \\
\hline
\end{tabular}

trauma (19). A new classification of splenic trauma, Baltimore Classification (Table 6), takes into account the presence of active bleeding on CT or extravasation of the contrast agent, which is the major prognostic factor (4). In patients who are hemodynamically unstable or have significant blood loss, angioembolization may be an effective hemostatic alternative to laparotomy for splenic, renal, or adrenal lesions if the procedure can be performed immediately $(4,16)$. Hagiwara et al. (20) thus demonstrated in a series of 269 patients with abdominal lesions with a grade of at least III $100 \%$ success for hemostatic embolization, especially in cases of multiple hemorrhagic outbreaks. For liver damage, angioembolization may be considered only in certain well-selected cases, as a firstline treatment, but this should be regularly followed by a laparotomy with additional hemostasis (4).

Although there were no such situations in our study, the risk of abdominal hyper pressure after severe abdominal trauma should always be considered, when the monitoring of intra-abdominal pressure is recommended for early detection of abdominal compartment syndrome. Intra-abdominal pressure greater than $20 \mathrm{mmHg}$, associated with organ dysfunction defines abdominal compartment syndrome and requires emergency treatment (4). A literature review found a prevalence of abdominal compartment syndrome of $0.2 \%$ to $20 \%$ after abdominal trauma (21). Risk factors 
for this syndrome are a BMI $\geq 27$, an APACHE II score $\geq 18$, abdominal distension, the need for controlled ventilation with a positive expiratory pressure $\geq 7 \mathrm{~cm} \mathrm{H} 2 \mathrm{O}$, the existence of shock, massive transfusions and the need for significant volume recovery (21). Without treatment, mortality from abdominal compartment syndrome is $90 \%$. Early treatment with laparostomy reduces the complications associated with abdominal compartment syndrome $(22,23)$.

In our study, patients with a favorable course of NOT were discharged after periods ranging from 5 days to 10 days, with an average of 6,6 days. These patients discharged early needed to be able to return to the hospital for clinical and imagistic monitoring. In the case of severe abdominal injury (grade $\geq$ III) treated with NOT, experts suggest hospitalization for clinical and biological monitoring for at least 3 to 5 days, in an intensive care unit for at least the first 24 hours, then in a surgical ward. The objective of monitoring is to detect the occurrence of bleeding and / or infectious complications. Most of these complications occur in the first 5 days $(24,25)$. In our study there was a patient approached by NOT, in whom the CT examination performed less than 48 hours after admission revealed an appreciable hemoperitoneum, forcing surgery. The authors claim that the risk of bleeding (secondary organ rupture, recurrence or persistence of bleeding) is maximum in the first 24 hours, justifying monitoring in an intensive care unit during this period $(25,26)$. The total duration of the supervision varies according to type and localization of the lession. Smith et al. published in 2008, from the largest national database in the US, the evolution of over 21,000 closed spleen trauma treated by NOT and showed that over $95 \%$ of secondary hemorrhages were diagnosed within 3 days (27). During this time, it is not necessary for the patient to stay in bed $(28,29)$. The duration of monitoring depends on the severity of the lesions observed and the patient's domicile. The risk of bleeding complications is maximum in the first days after the injury and then decreases slowly. $92 \%$ of these occur in the first 6 days after the accident (13). The initial splenic lesion may remain undetected by CT due to radiological artifacts or if only a CT examination without contrast has been performed. For this reason, for any posttraumatic hemoperitoneum, even of low volume, the tomography should be repeated, looking for a splenic lesion that was not detected on the initial abdominal ultrasound or CT scan. In France, the period of surveillance after splenic trauma varies depending on the severity of the injury, averaging about 15 days. Discharge from day 7 may be feasible if a contrast-enhanced CT scan is performed prior to discharge to rule out subcapsular hematoma or early pseudoaneurysm. Another condition for early discharge is that the patient has the necessary conditions to allow a prompt return to the hospital in case of emergency. In all patients included in the NOT protocol, we performed CT tests with contrast at intervals ranging from 24 hours to 5 days. The value of an early control CT 48 hours after hospitalization was demonstrated in a Canadian study, where due to this protocol, the success rate of NOT increased from $88 \%$ to $99.6 \%$ (30). The purpose of this CT scan is not so much to follow the lesion, but to detect a pseudoaneurysm or extravasation of the contrast substance, which would require interventional treatment. Velmahos et al. showed that for closed spleen trauma, the combination of extravasation spot size $>15$ $\mathrm{mm}$, hypotension $<100 \mathrm{mmHg}$ and grade $\geq$ III had a positive predictive value of $100 \%$ for secondary hemorrhage (31).

The major obstacle in applying the full protocol to our patients according to data available at this time in the literature, including influencing the inclusion criteria in the study was the inability to ensure the continuity of interventional radiology service, especially important in performing splenic artery embolization (SAE) or hepatic. In the series by Gaarder et al. (32), the overall spleen rescue rate increased from $57 \%$ to $75 \%$ due to SAE. Published series of splenic embolizations (performed only in patients who were not 
in hemorrhagic shock) revealed indications for SAE include: CT evidence of contrast extravasation, pseudoaneurysm or arteriovenous fistula, grade IV or $\mathrm{V}$ ruptures, massive hemoperitoneum, multiple severe trauma (33). In France, a consensus favors SAE either if contrast leakage is detected in a stable or stabilized patient or if pseudoaneurysm develops (34). Performing SAE requires the availability of an experienced radiologist 24 hours a day and an equipped interventional radiology room adjacent to the trauma reception center. The ability of the SAE to fully maintain the immune function of the spleen is uncertain. However, SAE has a complication rate of about $20 \%$ in some series (13). The most common complications were persistent bleeding, splenic infarction, migration of embolization particles, thrombosis of the vascular access site, wound infection at the access site, renal failure related to the contrast substance or late pancreatic pseudocyst. However, in two recent series that reported the follow-up of over 250 cases of splenic trauma, the rate of severe specific complications of SAE was less than $4 \%$, and the rate of technical success was greater than $96 \%(34,35)$. It should be noted that the current deaths related to splenic trauma are largely due to delayed laparotomy, lack of monitoring or if the abdominal trauma has gone unnoticed (33). When deciding on the NOT of splenic trauma, it is imperative to consider the possibility of other associated intra-abdominal injuries $(34,36,37,38)$. The most commonly associated intra-abdominal injuries involve the diaphragm and pancreas. In a patient with persistent abdominal pain, the possibility of abdominal compartment syndrome (ACS) should be considered. Although the risk of progression to a genuine ACS is low, it justifies measuring intravesical pressure when in doubt. In cases of ACS with unfavorable evolution, manifested by significant pain, oliguria, azotemia and ventilatory difficulties, a surgical examination should be performed at least for the evacuation of hemoperitoneum. The most common late complications after
NOT for spleen trauma are: splenic pseudocyst, pseudoaneurysm, arteriovenous fistula (AVF) (13).

\section{Conclusions}

We have successfully applied a NOT protocol tailored to our hospital conditions to more than a quarter of patients. The main obstacle to include more patients (possibly with larger lesions than grade III, or with blood collections greater than $500 \mathrm{ml}$ ) in the NOT protocol was the impossibility of ensuring a non-stop activity of the interventional radiology service.

FAST ultrasound, although with lower sensitivity compared to CT, was the basis of the emergency surgical indication in 5 cases, without the need for superior imaging.

Contrast-enhanced CT examination, performed in all patients, remains the basis for NOT initiation, providing the necessary data on the degree of liver or splenic lesion, the size of blood collections, and extravasation of the contrast substance but also an essential imaging exploration in assessing NOT efficacy.

Angioembolization was successfully performed in 2 cases, where CT examination and angiography showed contrast extravasation.

Monitoring of NOT cases should be well quantified and consists of a contrast-enhanced CT examination, for control, performed in our study at periods ranging from 24 hours to 5 days after hospitalization.

There was only one case included in the NOT, that was operated laparoscopically, but most authors emphasize that this should not be considered a failure of the method.

\section{Conflict of Interest}

The authors declare no conflicts of interests.

\section{Ethical Statement}

All procedures performed were in accordance with the ethical standards of the 1964 Helsinki Declaration and its later amendments. 


\section{References}

1. D. Eyraud ${ }^{\star}$, J. Grairia, Prise en charge d'un traumatisme hépatosplénique, Le Congrès Infirmiers, Infirmier(e)s anesthésistes diplômé(e)s d'état. 2013 Sfar.

2. Fourtanier G, Sledzianowski JF, Acevedo C, Suc B. Traumatismes hépatiques : diagnostic et traitement. Encycl Méd Chir (Elsevier Paris) Chirurgie 7-032-A10. 2000. 11 p.

3. Grande CM, Stene JK. Mechanisms of injury: etiologies of trauma. In : Stene JK, Grande CM, Eds. Trauma anesthesia. Baltimore : Williams \& Wilkins; 1991.p. 37-63

4. P Bouzat, G Valdenaire, T Gauss, J Charbit, C Arvieux, P Balandraud. Prise en charge du traumatisme abdominal grave de l'adulte : les 48 premières heures, Recommandations Formalisées d'Experts, RFE commune SFAR SFMU en association avec : AFC, AFU, SFRI et l'EVG, validé par le Conseil d'Administration de la SFAR et le Conseil d'Administration de la SFMU, 2019.

5. Press GM, Miller SK, Hassan IA, Alade KH, Camp E, Junco DD, Holcomb JB. Prospective evaluation of prehospital trauma ultrasound during aeromedical transport. J Emerg Med. 2014:47(6):638-45.

6. O'Dochartaigh D, Douma M. Prehospital ultrasound of the abdomen and thorax changes trauma patient management: A systematic review. Injury. 2015;46(11):2093-102.

7. Stengel D, Leisterer J, Ferrada P, Ekkernkamp A, Mutze S, Hoenning A. Point-of-care ultrasonography for diagnosing thoracoabdominal injuries in patients with blunt trauma. Cochrane Database Syst Rev. 2018;12: CD012669.

8. Zieleskiewicz L, Fresco R, Duclos G, Antonini F, Mathieu C, Medam S, et al. Integrating extended focused assessment with sonography for trauma (eFAST) in the initial assessment of severe trauma: Impact on the management of 756 patients. Injury. 2018; 49(10):1774-80.

9. Zhang Z, Hong Y, Liu N, Chen Y. Diagnostic accuracy of contrast enhanced ultrasound in patients with blunt abdominal trauma presenting to the emergency department: a systematic review and meta-analysis. Sci Rep. 2017;7(1):4446

10. Sierink JC, Treskes K, Ewards MJ, den Hartog D, Dijkgraaf MG, Luitse JS et al. Immediate total-body CT scanning versus conventional imaging and selective CT scanning in patients with severe trauma (REACT-2): a randomised controlled trial. Lancet. 2016;388(10045):673-83

11. Neal MD, Peitzman AB, Forsythe RM, Marshall GT, Rosengart MR, Alarcon LH, et al. Over reliance on computed tomography imaging in patients with severe abdominal injury: is the delay worth the risk? J Trauma. 2011;70(2): 278-84.

12. Clarke JR, Trooskin SZ, Doshi PJ, Greenwald L, Mode CJ. Time to laparotomy for intra-abdominal bleeding from trauma does affect survival for delays up to 90 minutes. The Journal of Trauma: Injury, Infection, and Critical Care. 2002;52(3):420-5.

13. Girard E, Abba J, Cristiano N, Matthieu S. Management of splenic and pancreatic trauma. J Visc Surg. 2016;153(4 Suppl):45-60

14. Changes in the management of injuries to the liver and spleen. Richardson JD. J Am Coll Surg. 2005;200:648-69.

15. Tinkoff G, Esposito TJ, Reed J, Kilgo P, Fildes J, Pasquale M, et al. American Association for the Surgery of Trauma Organ Injury Scale I: spleen, liver, and kidney, validation based on the National Trauma Data Bank. J Am Coll Surg. 2008;207(5):646-55.

16. Haan JM, Bochicchio GV, Kramer N, Scalea TM. Nonoperative management of blunt splenic injury: a 5-year experience. J Trauma. 2005;58:492-8.

17. Sabe AA, Claridge JA, Rosenblum DI, Lie K, Malangoni MA. The effects of splenic artery embolization on nonoperative management of blunt splenic injury: a 16-year experience. J Trauma. 2009;67:56.

18. YC Wang, CY Fu, YF Chen, CH Hsieh, SC Wu, CC Yeh Role of arterial embolization on blunt hepatic trauma patients with type I contrast extravasation.. Am J Emerg Med. 2011;29:1147-51.

19. Brault-Noble G, Charbit J, Chardon P, Barral L, Guillon F, Taourel P, et al Age should be considered in the decision making of prophylactic splenic angioembolization in nonoperative management of blunt splenic trauma: A study of 208 consecutive civilian trauma patients. J Trauma Acute Care Surg. 2012;73:1213-1220.

20. Hagiwara A, Murata A, Matsuda T, Matsuda H, Shimazaki S. The usefulness of transcatheter arterial embolization for patients with blunt polytrauma showing transient response to fluid resuscitation. J Trauma. 2004;57:271-6; discussion 276-7.

21. Reintam Blaser A, Regli A, De Keulenaer B, Kimball EJ, Starkopf L, Davis WA, et al. Incidence, Risk Factors, and Outcomes of Intra-Abdominal (IROI) Study Investigators. Incidence, Risk Factors, and Outcomes of IntraAbdominal Hypertension in Critically III Patients-A Prospective Multicenter Study (IROI Study). Crit Care Med. 2019;47:535-542.

22. Murphy PB, Parry NG, Sela N, KeLeslie, Vogt K, Ball I. Intra-Abdominal Hypertension Is More Common Than Previously Thought: A Prospective Study in a Mixed Medical-Surgical ICU. Crit Care Med. 2018;46:958-964.

23. Balogh Z, McKinley BA, Holcomb JB, Miller CC, Cocanour CS, Kozar RA, et al. Both primary and secondary abdominal compartment syndrome can be predicted early and are harbingers of multiple organ failure. J Trauma. 2004; 54:848-59; discussion 859-61.

24. Fakhry SM, Brownstein M, Watts DD, Baker CC, Oller D. Relatively short diagnostic delays ( $<8$ hours) produce morbidity and mortality in blunt small bowel injury: an analysis of time to operative intervention in 198 patients from a multicenter experience. J Trauma. 2000;48:408-14.

25. Peitzman AB, Heil B, Rivera L, Federle MB, Harbrecht BG, Clancy KD, et al. Blunt splenic injury in adults: Multi-institutional Study of the Eastern Association for the Surgery of Trauma. J Trauma. 2000;49:177-87.

26. Hagiwara A, Murata A, Matsuda T, Matsuda H, Shimazaki S. The efficacy and limitations of transarterial embolization for severe hepatic injury. J Trauma. 2002;52:1091-6.

27. Smith J, Armen S, Cook CH, Martin LC. Blunt splenic injuries: have we watched Iong enough? J Trauma. mars 2008:64(3):656-63; discussion 663-665.

28. London JA, Parry L, Galante J, Battistella F. Safety of early mobilization of patients with blunt solid organ injuries. Arch Surg Chic III 1960. oct 2008; 143:972-6; discussion 977.

29. Wang E, Inaba K, Byerly S, Mendelsberg R, Sava J, Benjamin E, et al. Safety of early ambulation following blunt abdominal solid organ injury: A prospective observational study. Am J Surg. 2017;214(3):402-406

30. Leeper WR, Leeper TJ, Ouellette D, Moffat B, Sivakumaran T, CharykStewart $\mathrm{T}$, et al. Delayed hemorrhagic complications in the nonoperative management of blunt splenic trauma: early screening leads to a decrease in failure rate. J Trauma Acute Care Surg. 2014;76:1349-53

31. Velmahos GC, Zacharias N, Emhoff TA, Feeney JM, Hurst JM, Crookes BA, et al. Management of the most severely injured spleen: a multicenter study of the Research Consortium of New England Centers for Trauma (ReCONECT). Arch Surg. 2010;145:456-60

32. Gaarder C, Dormagen JB, Eken T, Oddvar Skaga N, Einar Klow N, PillgramLarsen J, et al. Nonoperative management of splenic injuries: improved results with angioemboliza-tion. J Trauma. 2006;61(1):192-8.

33. Olthof DC, Joosse P, van der Vlies CH, de Haan RJ, Goslings JC. Prognostic factors for failure of non-operativemanagement in adults with blunt splenic injury: a system-atic review. J Trauma Acute Care Surg 2013;74:546-57.

34. Frandon J, Rodière M, Arvieux C, Frandon J, Rodière M, Arvieux C, et al. Blunt splenic injury:outcomes of proximal versus distal and combined splenicartery embolization. Diagn Interv Imaging. 2014;95(9):825-31.

35. Skattum J, Naess PA, Eken T, Gaarder C. Refining therole of splenic angiographic embolization in high-gradesplenic injuries. J Trauma Acute Care Surg. 2013;74:100-3 [discussion103-4].

36. Peitzman AB, Harbrecht BG, Rivera L, Heil B, Easternassociation for the surgery of trauma multiinstitutionaltrials workgroup. Failure of observation of blunt splenicinjury in adults: variability in practice and adverse consequences. J Am Coll Surg. 2005;201:179-87.

37. Miller PR, Croce MA, Bee TK, Malhotra AK, Fabian TC. Associated injuries in blunt solid organ trauma: implicationsfor missed injury in non-operative management. J Trauma. 2002;53:238-42 [discussion 242-4].

38. Socea B, Bogaciu C, Carâp AC, Baleanu DV, Davitoiu DV, Tenea-Cojan TS, et al. Nonoperative management of high-grade splenic injury. A review of the literature and case report. Rom. J. Mil. Med. 2020;CXXIII:21-25. 